\title{
Reducing community dyspepsia drug costs: a controlled trial
}

\author{
R M Valori, C M Brown, P Strangeways, M Bradburn
}

\begin{abstract}
Background-Dyspepsia drug costs account for nearly $0.5 \%$ of the National Health Service budget. We hypothesised that improved management of dyspepsia would lead to reduced drug costs.

Aim-To determine whether a multifaceted educational strategy for general practitioners aimed at improving quality of dyspepsia management can control dyspepsia costs without increasing demand for endoscopy.
\end{abstract}

Methods-A multifaceted educational intervention was delivered to general practitioners in West Gloucestershire but not to those in the east of the county. Dyspepsia drug costs, the primary outcome measure, were obtained from the Prescription Pricing Authority and compared between the two sides of the county. Referral rates for endoscopy, admission to the gastrointestinal bleed unit, and delayed diagnosis of gastric cancer were secondary measures recorded in West Gloucestershire only.

Results-Following the intervention, drug costs declined and then stabilised in West Gloucestershire. Drug costs peaked in the control group 15 months after those in the intervention group. Using an autoregressive integrated moving average model it was estimated the overall costs in the intervention group reduced by 57.9 pence per head of population per half year $(95 \%$ confidence interval 45.8-69.9 pence/half year; $p<0.0001)$ in comparison with the control group. This difference was maintained for three consecutive years resulting in a cumulative saving of $£ 1.13$ million. Referral rates for upper gastrointestinal endoscopy remained stable during the study period.

Conclusion-A multifaceted educational intervention for general practitioners designed to improve the quality of care of patients with dyspepsia is an effective means of controlling dyspepsia drug costs without increasing demand for endoscopy. (Gut 2001;49:495-501)

Keywords: dyspepsia; drug costs; general practitioners

Dyspepsia is a common problem that is managed in both primary and secondary care. Five per cent of new consultations in primary care are for dyspepsia and $1 \%$ of the population is endoscoped each year. ${ }^{12}$ During the last decade the costs of treating dyspepsia have escalated rapidly reaching a peak in the last quarter of 1997. Annual dyspepsia drug cost inflation during this period exceeded $10 \%$. In recent years the total costs of managing dyspepsia have consistently exceeded $1 \%$ of the National Health Service (NHS) budget.

There have been major changes in the management of dyspepsia recently. Open access endoscopy has become widespread, the causative role of Helicobacter pylori in peptic ulcer has been established, ${ }^{3}{ }^{4}$ there is now effective cytoprotection for non-steroidal anti-inflammatory drugs (NSAIDs), ${ }^{5}$ and proton pump inhibitors have revolutionised the management of reflux disease. ${ }^{6}$

In 1994 the government issued an Executive Letter" asking "..purchasers to develop and agree strategies for improving the cost effectiveness of prescribing across the primary/ secondary care interface". However, there was little incentive for either primary or secondary care to react to initiatives from health authorities to change their behaviour. Fundholding general practitioners (GPs) had incentive to control their prescribing costs but not to work directly with secondary care in the spirit of the Executive Letter.

Common symptoms managed in primary care, very high costs, new evidence in a rapidly changing field, and directives from central government provided an opportunity to test the effectiveness of an educational intervention delivered in primary care. Using a controlled before and after study design, this investigation tested the hypothesis that an evidence based educational intervention in primary care, designed to improve the quality of care of dyspepsia, would control dyspepsia drug costs. It was hypothesised that better quality care would lead to reduced drug costs because of more widespread eradication of $H$ pylori for peptic ulcer, a more active stepdown approach for reflux symptoms, and a switch from ranitidine to generic cimetidine.

The intervention used several educational techniques and it was delivered in primary care in West Gloucestershire. Dyspepsia drug costs was the primary outcome measure. Drug costs were compared between West and East Gloucestershire for three years after the intervention.

Abbreviations used in this paper: NHS, National Health Service; NSAIDs, non-steroidal anti-inflammatory drugs; GPs, general practitioners; EPOC, Effective Practice and Organisation of Care; FHSA, Family Health Services Authority; ARIMA, autoregressive integrated moving average. 
Methods

TARGET POPULATION AND SETTING

Intervention group

GPs and their trainees within the referral population of the Gloucestershire Royal Hospital NHS Trust were invited to participate in the study. The area included the Stroud, Gloucester, and Forest of Dean wards of West Gloucestershire covering a patient population of nearly 325000 of mixed urban and rural type. There were no exclusions within this geographical boundary. West Gloucestershire pioneered open access endoscopy ${ }^{8}$ which is available in the main hospital and two community hospitals. About 1800 open access procedures are performed each year $(0.5 \%$ of the population/year).

\section{Control group}

East Gloucestershire acted as the control area with a population of 250000 . This area includes the Cheltenham and Cotswolds wards. GPs refer patients from this area to the Cheltenham General Hospital. Cheltenham General Hospital has an open access endoscopy service that also performed endoscopies in about $0.5 \%$ of the population each year.

Differences between intervention and control groups

The demographics of each population are similar. Open access endoscopy has been available in East Gloucestershire for 10 years less than in Gloucester but the nature of the service (mode of access and type of endoscopists) is very similar. At the time of the intervention the proportion of fundholders was higher in the East $(46 \%$ v $26 \%)$. Prior to the intervention, drug costs had been escalating on both sides of the county at a similar rate. The actual cost of dyspepsia drugs in the East lagged behind that in the West by six months. At any particular moment prior to the intervention, drug costs in the East were approximately $10 \%$ below those in the West.

Despite these differences, East Gloucestershire was considered a good control group because it was thought that the main difference (drug costs) could be adjusted for in the subsequent analysis. Furthermore, the other important difference (more fundholders in the East) was thought more likely to have a controlling effect on drug costs, countering rather than inflating any observed effect of the intervention.

\section{INTERVENTION}

Ten workshops, delivered in primary care in the first quarter of 1995, formed the main constituent of the intervention. Additional educational techniques included stakeholder generated guidelines, handouts, and reminders. The intervention was carried out in four phases.

Phase 1

An advisory panel consisting of two consultant gastroenterologists (one physician and one surgeon), two senior registrars in gastroenterology, the medical director of the Family Health
Services Authority (FHSA), a microbiologist with a special interest in $H$ pylori, two local GPs, and representatives from the hospital pharmacy formulated a list of key issues. These key issues were divided into three sections: new evidence (for example, effect of $H$ pylori eradication on peptic ulcer); commonly asked questions (for example, do patients with typical reflux symptoms need endoscopy?); and local audits of rare but important outcomes (for example, gastric cancer, oesophageal adenocarcinoma, and complications of NSAIDs).

Medline searching was supplemented with proceedings of the major American and British gastroenterology meetings held in the previous two years, hand searching of the major gastroenterology journals, and relevant citations of retrieved articles. Embase was searched for drug related questions.

The evidence was put into local context (local data, resource, service pattern, and knowledge) and prioritised in terms of the

- strength of the evidence,

- importance of the clinical problem,

- probability of achieving a change in practice, and

- expected value added of a change in practice in terms of patient welfare and resource use. It was agreed that the guidelines distributed to GPs should contain mainly therapeutic messages because the recommendations for these were relatively clear cut compared with those regarding diagnosis and management which were more suited to the workshop format.

Phase 2

In December 1994, all GPs in West Gloucestershire were sent the written guidelines and an invitation to attend a workshop on dyspepsia close to their own practice. Ten workshops were located in three sectors, giving each GP at least three opportunities to attend locally.

Phase 3

The workshops were held in the first quarter of 1995. Each workshop followed a semistructured format lasting 90 minutes and was free of drug company sponsorship.

A single gastroenterologist (RMV) facilitated the workshops. When good evidence was available it was emphasised; otherwise, a pragmatic approach building on the experience of the individual GP was advocated. GPs were encouraged to share their experiences of managing patients with dyspepsia. Information on local activity and outcome (for example, rates of gastric cancer, complications of NSAIDs, and dyspepsia drug costs) was used whenever possible. The workshops focused on four themes: indications for endoscopy; update on $H$ pylori; management of NSAID related dyspepsia; and cost effective prescribing for reflux symptoms. GPs were:

- discouraged from investigating younger patients (aged <55) without alarm symptoms if the purpose of endoscopy was to exclude cancer. ${ }^{9}$ This recommendation was balanced against randomised controlled evidence that 
early endoscopy reduces consultations in primary care and dyspepsia drug costs, ${ }^{10}$

- strongly encouraged to search for and eradicate $H$ pylori in the presence of peptic ulcer ${ }^{4}$ but not to expect a change in symptoms after eradication in other circumstances, ${ }^{11}$

- asked to avoid using NSAIDs if possible and only co-prescribe a protective agent in the very old ( $>85$ years) and in those with a previous history of peptic ulcer, and

- encouraged to titrate medication against symptoms in all but stricturing or bleeding reflux disease.

The recommendations made to GPs were similar to those subsequently released by the British Society of Gastroenterology. ${ }^{12}$

Phase 4

During 12 months after the workshops, three personalised letters were sent to all GPs in West Gloucestershire. These clarified responses to common questions and contained further recommendations about new formulations and new drugs: for example, using either omeprazole $10 \mathrm{mg}$ or lansoprazole $15 \mathrm{mg}$ in place of omeprazole $20 \mathrm{mg}$.

The therapeutic guidelines were adopted officially by the FHSA during the study period and distributed in an information leaflet to GPs in both the East and West sides of the county with regular reinforcement applied equally across the county by the pharmaceutical advisers of the FHSA. Thus the only changes that occurred at the time of the intervention that differed between East and West were the posted written guidelines, the workshops, and the personalised reminders.

OUTCOMES

Primary outcome

The primary outcome of the study was the cost of medications in section 1.3 of the British National Formulary (BNF). This section consists of antacids, antisecretory drugs $\left(\mathrm{H}_{2}\right.$ receptor blockers and proton pump inhibitors), Denol, sucralfate, and anticholinergics. Denol, sucralfate, and anticholinergics are responsible for only a tiny proportion of the costs of this section. The costs were derived from Prescription Pricing Authority data supplied to the Gloucestershire Health Authority. These were available six monthly until mid 1994 and quarterly thereafter. The costs are expressed in pence/head of population.

Secondary outcome (West Gloucestershire only) Endoscopy. Referral rate for open access endoscopy was the principal secondary outcome measure.

Costs of the intervention. This estimate included the time spent in meetings, searching and appraising evidence, preparing educational materials, organising and delivering the workshops, and preparing and distributing reminder letters. It excluded time for GPs to attend the workshops.
Other outcomes

The following audits performed during the study period provided additional dyspepsia related outcomes:

- admissions to the Gloucestershire Royal Gastrointestinal Bleed Unit (1994-97) and

- presenting features of gastric cancer in those less than 55 years of age in West Gloucestershire (1995-97).

\section{STATISTICAL METHODS}

The difference in prescribing costs between the intervention and control groups over time was analysed as an interrupted time series model, based on an autoregressive integrated moving average (ARIMA) model approach. For a series of cost measurements $C_{t}$ taken at time $t$, the basic ARIMA(p,d,q) model fitted is

$$
\mathrm{Y}_{\mathrm{t}}=\mathrm{bz}+\mu_{\mathrm{t}}+\varepsilon_{\mathrm{t}}
$$

where $Y_{t}$ is the (possibly differenced by factor d) time series, $=C_{t}$ if not differenced $(d=0)$; $b$ is the estimate of the change in $Y_{t}$ after post-intervention; and $\mathrm{z}=1$ if the intervention has occurred, 0 otherwise.

$\mu_{t}=\sum_{i=1}^{p} \rho_{i}\left(Y_{t-i}-b \times z_{t-i}\right)+\sum_{j=1}^{q} \theta_{j} \varepsilon_{t-j}+\varepsilon_{t}$

where $\rho_{\mathrm{i}}$ and $\theta_{\mathrm{j}}$ are the autocorrelation and moving average parameters, respectively, and $\varepsilon_{\mathrm{t}}$ is the residual. This reduces to the straightforward linear regression of $\mathrm{Y}$ on $\mathrm{z}$ when $\mathrm{p}=\mathrm{q}=0$ aside from a small adjustment to the standard error, and the terms $\rho_{\mathrm{i}}$ and $\theta_{\mathrm{j}}$ are dropped from the above equation.

Various models were fitted and the best selected by examination of the residual autocorrelations and partial autocorrelations. The period of analysis incorporates three years before and after the intervention. Only data for the first and third quarters were available until mid 1994 after which full quarterly data were available (table 1). Half yearly expenditure was analysed as the primary outcome, with half years taken from April to September and October to the following March, as this allows the cleanest break between the preintervention period (defined as until the end of March 1995) and the postintervention period (defined as times thereafter). It was assumed that the amount spent per region for the half years prior to 1994 was equal to twice that spent in the quarter in which the data were available.

A $p$ value of $5 \%$ or lower was considered statistically significant. All analyses were performed using version 6.0 of the Stata statistical package.

\section{Results}

\section{ATTENDANCE}

The workshops were popular with GPs because they were delivered in the community and because they were interactive and pragmatic. They were attended by $68 \%$ of those invited (123 of 180). Only two of 48 eligible practices did not send at least one representative. 
Table 1 Quarterly dyspepsia drug costs (section 1.3 of the British National Formulary) in West and East Gloucestershire for the period 1991-97, expressed as pence/quarter/head of population

\begin{tabular}{|c|c|c|c|c|c|}
\hline \multicolumn{3}{|c|}{ Timing of measurements } & \multicolumn{3}{|c|}{ Costs (pence/quarter/head of population) } \\
\hline Quarter & $\begin{array}{l}\text { Gap in } \\
\text { months }\end{array}$ & $\begin{array}{l}\text { Time from zero in } \\
\text { months }\end{array}$ & West & East & Difference West-East \\
\hline $1^{\star}$ & 2 & 3 & 4 & 5 & 6 \\
\hline $1-91$ & - & 0 & 90 & 75 & 15 \\
\hline $1-92$ & 12 & 12 & 117 & 99 & 18 \\
\hline $3-92$ & 6 & 18 & 120 & 102 & 18 \\
\hline $1-93$ & 6 & 24 & 126 & 117 & 9 \\
\hline $3-93$ & 6 & 30 & 159 & 132 & 27 \\
\hline $1-94$ & 6 & 36 & 150 & 138 & 12 \\
\hline $3-94$ & 6 & 42 & 170 & 155 & 15 \\
\hline $4-94$ & 3 & 45 & 185 & 169 & 16 \\
\hline $1-95$ & 3 & 48 & 186 & 181 & 5 \\
\hline $2-95$ & 3 & 51 & 180 & 184 & -4 \\
\hline 3-95 & 3 & 54 & 175 & 186 & -11 \\
\hline 4-95 & 3 & 57 & 178 & 192 & -14 \\
\hline $1-96$ & 3 & 60 & 186 & 200 & -14 \\
\hline $2-96$ & 3 & 63 & 185 & 198 & -13 \\
\hline $3-96$ & 3 & 66 & 186 & 201 & -15 \\
\hline $4-96$ & 3 & 69 & 181 & 197 & -16 \\
\hline $1-97$ & 3 & 72 & 178 & 189 & -12 \\
\hline 2-97 & 3 & 75 & 183 & 203 & -20 \\
\hline 3-97 & 3 & 78 & 184 & 199 & -15 \\
\hline 4-97 & 3 & 81 & 195 & 209 & -14 \\
\hline
\end{tabular}

${ }^{\star}$ Column 1, quarter measure was made (for example, 1-91=1st quarter of 1991); column 2, gap since the last measurement; column 3 , time since the first measurement; columns $4 / 5$, costs of dyspepsia drugs per head of population for that quarter; column 6, difference in costs between East and West.

The quarter in which the workshops were delivered is indicated in bold type.

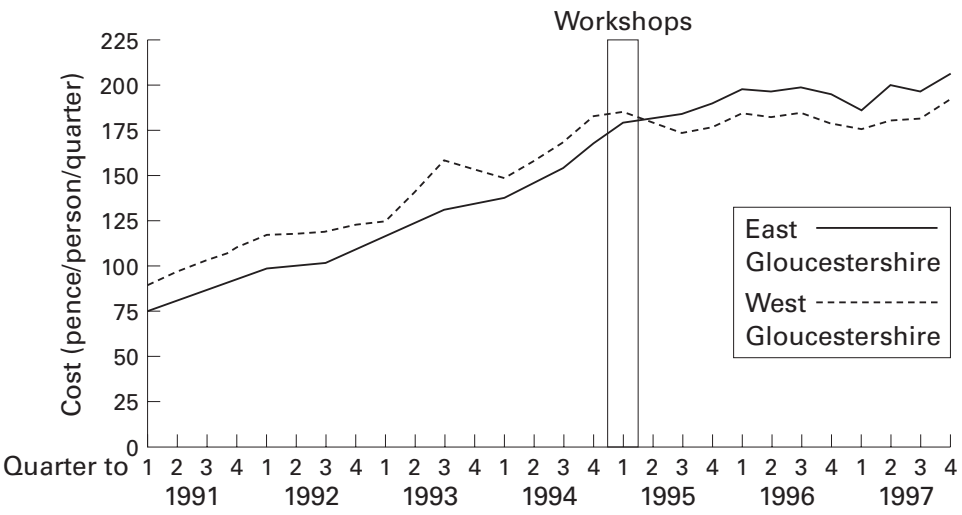

Figure 1 Dyspepsia drug costs in West and East Gloucestershire for 1991-1997.

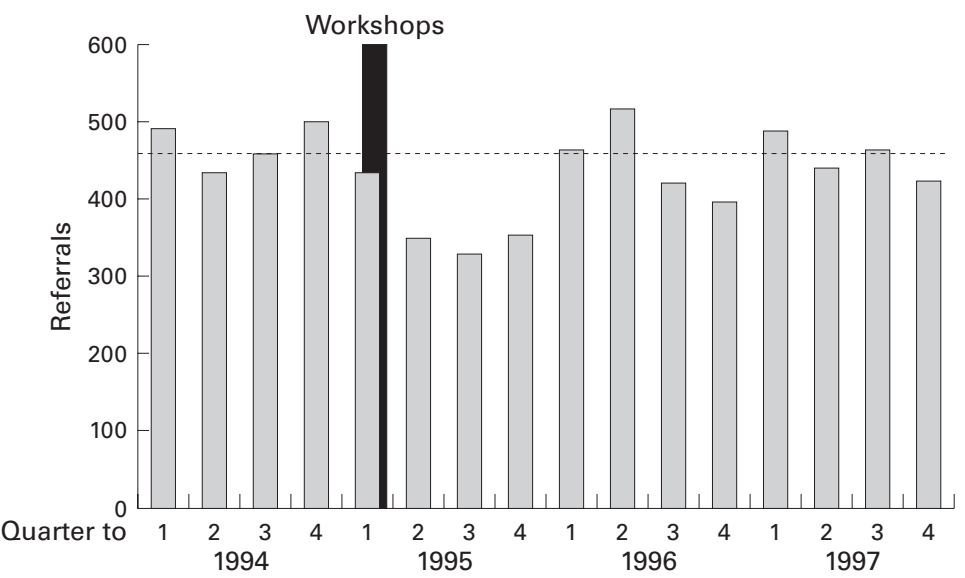

Figure 2 Referrals for open access endoscopy in West Gloucestershire for 1994-1997.

DRUG COSTS (TABLE 1, FIG 1)

No significant seasonality or autocorrelation was present among the difference in costs between West and East Gloucestershire over

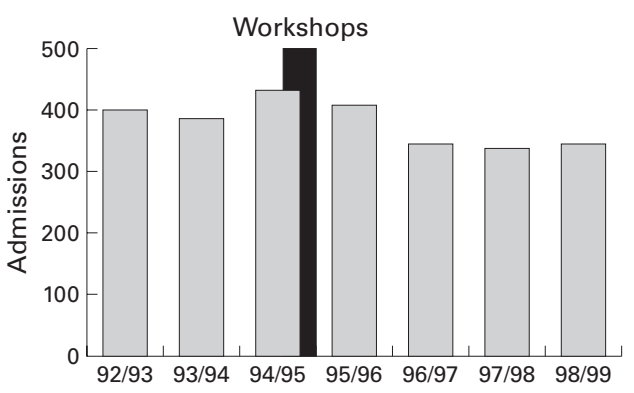

Figure 3 Admissions to the gastrointestinal bleed unit in West Gloucestershire for 1992-1999.

the period of this study. The intervention effect and its standard error, as estimated with ARIMA parameters, were therefore very similar to those observed when ordinary least squares regression was performed. We present results as derived from the latter model.

Initially, a basic model was fitted which contained one term to denote whether the intervention had occurred. The mean reduction in cost from 1995 onwards (the estimate $b$ in the model) was 57.9 pence per head of population per half year $(95 \%$ confidence interval 45.8-69.9 pence; $\mathrm{p}<0.0001)$. Further models were fitted which involved a term for the difference in costs in 1995 (the year of the intervention) separately to those in subsequent years, and interaction between time and intervention to test whether the impact of the intervention had remained constant throughout the duration of the study. This indicated a stable effect of the intervention over this period except for the first half year when the difference in costs compared with the preintervention baseline was smaller (46.3 pence per head) than in the subsequent years (average of the six half years 59.8 pence).

There was significantly greater expenditure in West Gloucestershire than in the East (by an average of 31.3 pence per head; $\mathrm{p}<0.0001$ ) prior to the intervention. A further more conservative analysis was carried out to investigate how much this may have influenced the findings had this trend not continued into the postintervention period. The baseline differences in costs were centred around a mean zero by subtracting 31.3 from all preintervention values. The estimated intervention effect would then be reduced to 26.5 pence per half year per head; however, this difference remained statistically significant $(\mathrm{p}<0.0001)$.

OPEN ACCESS ENDOSCOPY REFERRALS

Figure 2 illustrates the demand for open access endoscopy during the period 1994-97. The demand for endoscopy decreased in the months following the workshops, returning to baseline levels thereafter.

ADMISSIONS TO THE GASTROINTESTINAL BLEED UNIT

Admissions to the bleed unit increased by $10 \%$ in the year of the workshops and then declined to below baseline levels for the next two years (fig 3). 
Table 2 Breakdown of the costs of the intervention

\begin{tabular}{llr}
\hline Activity & Detail & Cost $(f)$ \\
\hline Steering group & Organisation, time spent meeting & 3500 \\
Searching/appraising & Time & 800 \\
Organising workshops & Time including liaison and invitations & 300 \\
Educational materials & Time, photocopying, and postage & 500 \\
Ten workshops & Time, travel and meals. Excludes GP time & 1200 \\
Reinforcement letters & Time and postage & 300 \\
Total & & 6600 \\
\hline
\end{tabular}

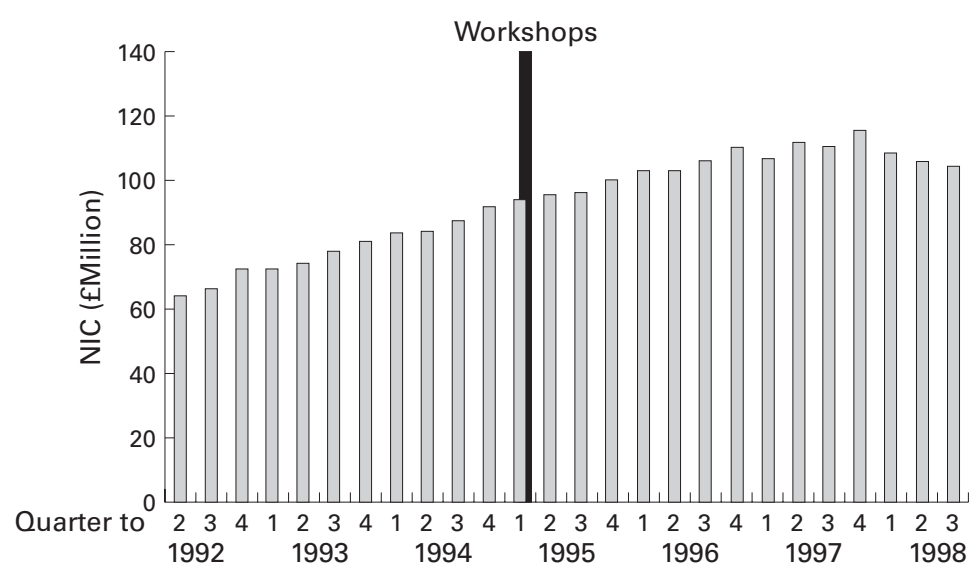

Figure 4 Costs of dyspepsia drugs in England and Wales for 1992-1998. NIC, net ingredient cost.
Gloucestershire (fig 4). Endoscopy referrals in West Gloucestershire declined temporarily after the workshops and then stabilised to baseline levels.

The estimated difference between drug costs in West and East Gloucestershire was 57.9 pence per head of population per half year (95\% confidence interval $45.8-69.9$ pence; $\mathrm{p}<0.0001)$. This difference was maintained for three years after the intervention. The total estimated saving for the three year period is $£ 1.13$ million (95\% confidence interval £0.89-1.36 million). A more conservative analysis, assuming identical expenditure in East and West Gloucestershire, estimated the savings to be 26.5 pence per half year (total savings of $£ 0.52$ million). The cost of the intervention $(£ 6600)$ is small compared with the savings. The intervention is generalisable to other district general hospital settings that provide care for at least $50 \%$ of the population. If the intervention was applied across the country we estimate a national saving of at least $£ 25$ million per year over a three year period. This estimation depends on the fraction of the population that is served by district general hospitals similar to that provided by Gloucestershire Royal Hospital.

There are two limitations to this study: it was not a randomised trial and important outcomes such as symptoms and GP consultations were not measured. The Cochrane Review Group on Effective Practice and Organisation of Care (EPOC) recognises that in studies involving a change in clinical practice it is not always possible to use a randomised design. ${ }^{13}$ This view was expressed in a systematic review of the effect of guidelines on professional practice published in the Effective Health Care Bulletin in $1994 .{ }^{14}$ The Health Technology Assessment programme recognises study designs other than randomised controlled trials in this area of research ${ }^{15}$ and published guidelines for evaluating "organisation level" interventions.

It was thought that a randomised design was not possible in this study because a local opinion leader led intervention, directed at a close knit primary care community, would be subject to excessive contamination of either GPs or their practices. It was predicted that contamination across the medical communities of East and West Gloucestershire would be less intense and less immediate. The study fulfils the EPOC criteria for a control before and after study design ${ }^{13}$ because there are objective data points for the primary outcome measure for three years before and after the intervention. EPOC guidelines on critical appraisal of alternative study designs use seven criteria to assess methodological quality. ${ }^{13}$ In this study three of the seven criteria were not met: the baseline measure (drug costs) was not identical in the two groups; the groups did not have identical baseline characteristics; and contamination could not be avoided.

It is not possible to know whether the difference in preintervention costs represents a true difference in behaviour or population characteristics that dictated subsequent events. For example, higher preintervention costs in the 
West might indicate greater potential for cost control or more challenging behaviour to change. Thus the preintervention differences may have exaggerated or diminished the observed effect.

Baseline characteristics differed in two ways. There were more fundholders in the East and open access endoscopy had been available for longer in the West. More fundholders is likely to reduce the observed effect of the intervention because fundholders are better able to control drug costs. ${ }^{16}{ }^{17}$ More experience of open access endoscopy might increase the effect because GPs, through this experience, may be more willing to embrace change. ${ }^{18}$ Finally, contamination could not be avoided in this study but contamination is more likely to lead to a reduction in effect size. Thus there are factors that may have influenced the result of this non-randomised study; however, it is likely that the positive and negative effects of these factors are well balanced. Furthermore, we believe that these effects are small in comparison with the magnitude of the observed effect of the intervention.

The principal outcome of this study addressed was resource use. Technically, it could be described as a cost minimisation study but such a study requires no change in clinical outcomes. ${ }^{19}$ Ideally the outcomes such as symptoms, consultation in primary and secondary care, time lost from work, and satisfaction with care would be measured. However, it was not considered feasible, even with substantial resource, to capture every dyspepsia episode to obtain this type of information because identifying the reason for a consultation is not straightforward. ${ }^{20}$ However, there are good reasons for believing that symptom control was not significantly affected by the intervention.

Once recurrent peptic ulceration has been cured with eradication of $H$ pylori the majority of expenditure on dyspepsia drugs is on control of reflux symptoms. There was universal agreement among the GPs during the workshops that once patients have good control of their reflux symptoms they are very reluctant to change or reduce their medication. This resistance to change was discussed vigorously in every workshop. It constituted the main patient barrier to reducing dose or switching medication to something cheaper. This patient behaviour indicates that a significant change in symptoms is unlikely to have occurred.

A further concern is that reducing drug costs leads to increased expenditure in other areas or to increased adverse clinical events. In this study demand for endoscopy was unaffected (it declined initially). Detecting a change in adverse clinical events is very difficult because they are rare. We measured what was dyspepsia related and feasible to measure through an auditing process: admissions to the gastrointestinal bleed unit and delays in diagnosis for gastric cancer in younger patients. While we appreciate the limitations of these items and how they were measured, they paint a broader picture that indicates that there have been no negative consequences to the intervention.
There has been one previous study of the effect of implementing guidelines on dyspepsia drug costs. This study showed a small rise in drug costs following the intervention. ${ }^{21}$ This was a randomised controlled trial conducted in primary care. The intervention occurred when open access endoscopy was not available and at a time when proton pump inhibitors were not in widespread use. Thus it is not generalisable to other clinical settings or directly comparable to this study.

There is good evidence that single interventions and certain types of interventions such as printed guidelines and didactic lectures are not effective at changing clinical practice. ${ }^{22}$ Furthermore, a recent Cochrane Review has shown that educational outreach visits are effective in changing professional practice. ${ }^{23}$ This study used several educational or "change" techniques such as stakeholder involvement identifying key issues and developing guidelines, interactive workshops delivered by a local opinion leader, handouts, and reminders. Peer support was an unexpected change force evident during the workshops. A peer declaring he has achieved what others say is impossible is a powerful catalyst for change. Peer support has been identified as one of the strongest instruments of change in primary care. ${ }^{24}{ }^{25}$ For example, several doctors were able to share their experience of eradicating $H$ pylori in patients with peptic ulcer or stepping down antireflux medication.

Most consultants will argue they do not have time to reproduce the intervention and it may be possible to achieve a similar effect without consultant input. However, the intervention was not time consuming and there are potential benefits for the consultant. Qualitative research indicates that primary care doctors perceive that their consultant colleagues do not understand their educational needs. ${ }^{26}$ There is probably much more consultants fail to appreciate. The interactive nature of such an intervention provides an opportunity for consultants to improve their understanding of the educational and service needs of GPs.

It could be argued that the intervention is not generalisable to other settings in the UK because Gloucestershire GPs have more experience with open access endoscopy ${ }^{8}$ and are therefore more receptive to an educational intervention on the management of dyspepsia. However, now, more than six years on, GPs in other parts of the country should be in a similar position to that which the Gloucestershire GPs were in when the intervention was carried out. We believe therefore that the intervention is generalisable to other district general hospital settings and if it was applied across the country there might be savings of around $£ 25$ million/year for three consecutive years.

In conclusion we have shown that a multifaceted evidence based educational strategy centred around interactive workshops and delivered in primary care is popular with GPs. It leads to significant and substantial benefits in health care costs without measurable adverse consequences. The changes in the NHS make application of the intervention easier than it has 
been. ${ }^{27}$ Primary care groups will need and demand more interaction with secondary care if they are to use their budgets most effectively without alienating their secondary care colleagues. Furthermore, complete devolution of community drug budgets, and the ever present squeeze on resource, will provide GPs with the incentive to approach their consultant colleagues to work together to control costs and use scarce resources in the most productive way.

1 Brown C, Rees WDW. Dyspepsia in general practice. BMF 1990;300:829-30.

2 Scott B. Endoscopic demands in the 90s. Gut 1990;31:1256 .

3 Marshall BJ, Warren JR. Unidentified curved bacilli on gastric epithelium in active chronic gastritis. Lancet 1984;1 1311-15

4 NIH Concensus Conference. Helicobacter pylori in peptic ulcer disease. FAMA 1994;272:65-9.

5 Silverstein FE, Graham DY, Senior JR, et al. Misoprostol reduces serious gastrointestinal complications in patients with rheumatoid arthritis receiving nonsteroidal antiinflammatory drugs: a randomized double-blind, placebocontrolled trial. Ann Intern Med 1995;123:241-9.

6 Dent J, Yeomans ND, Mackinnon M, et al. Omeprazole v ranitidine for prevention of relapse in reflux oesophagitis. A controlled double blind trial of their efficacy and safety. Gut controlled doub

7 Department of Health. Purchasing and prescribing. London: Department of Health 1994; Executive Letter.

8 Gear MWL, Barnes RJ. Endoscopic studies of dyspepsia in a general practice. BMF 1980;280:1136-7.

9 Christie J, Shepherd NA, Codling BW, et al. Gastric cancer below the age of 55 . Implications for screening patient with uncomplicated dyspepsia. Gut 1997;41:513-17.

10 Bytzer P, Hansen JM, Schaffalitzky de Muckadell OB. Empirical H2-blocker therapy or prompt endoscopy in management of dyspepsia. Lancet 1994;343:811-16.

11 Talley NJ. A critique of therapeutic trials in Helicobacter pylori positive functional dyspepsia. Gastroenterology 1994; 106:1174-83.

12 BSG Guidelines: Dyspepsia Management Guidelines. London: British Society of Gastroenterology, 1996; 1 .
13 Bero LA, Grilli R, Grimshaw JM, et al, eds. The Cochrane Effective Practice and Organisation of Care Review Group Module of the Cochrane Database of Systematic Reviews, 4th edn. London: Cochrane Library, 1998.

14 NHS Centre for Reviews and Dissemination. Implementing clinical practice guidelines. Effective Health Care 1994;8:211.

15 Ukoumunne OC, Gulliford MC, Chinn S, et al. Methods for evaluating area-wide and organisation-based interventions in health and health care: a systematic review. Health Technol Assess 1999;3:(5).

16 Harris M, Scrivener G. Fundholders' prescribing costs: the first five years. BMF 1996;313:1531-4

17 Stewart-Brown S, Surender R, Bradlow J, et al. The effects of fundholding in general practice on prescribing habits three years after introduction of the scheme. BMF three years after

18 Lomas J. Retailing research: increasing the role of evidence in clinical services for childbirth. Milbank $Q$ 1993;71:43975

19 Lockett T. Health Economics for the uninitiated. Oxford: Radcliffe Medical Press, 1996.

20 Woloshynowych M, Valori RM, Salmon P. General practice patients' beliefs about their symptoms. Br $\mathcal{F}$ Gen Pract 1998;48:885-9.

21 Jones RH, Lydeard S, Dunleavy J. Problems with implementing guidelines: a randomised controlled trial of consensus management of dyspepsia. Qual Health Care 1993;2:217-21.

22 NHS Centre for Reviews and Dissemination. Getting evidence into practice. Effective Health Care Bulletin 1999;5:(1).

23 O'Brien MA, Oxman AP, Davis DA, et al. Educational outreach visits: effects on professional practice and healthcare outcomes. Cochrane Review. In: The Cochrane Library. Oxford: Update Software, 2000; issue 4.

24 Allery LA, Owen PA, Robling MR. Why general practitioners and consultants change their clinical parctice: a critical incident study. BMF 1997;314:874.

25 Eccles $\mathrm{M}$, Soutter J, Bateman DN, et al. Influences on prescribing in non-fundholding general practices. $\mathrm{Br} f \mathrm{Gen}$ Pract 1996;46:287-90.

26 Marshall MN. Qualitative study of educational interaction between general practitioners and specialists. BMF 1998; 316:442-5.

27 Department of Health. The new NHS: modern and dependable: developing primary care groups. London: Department of Health, 1998. 